\title{
Taxonomia de letras capitulares contemporâneas
}

\author{
Taxonomy of contemporary drop caps
}

\author{
Airton Cattani, Davi Frederico do Amaral Denardi
}

capitulares, tipografia, projeto gráfico, publicações periódicas

\begin{abstract}
Letras capitulares são um recurso gráfico muito utilizado para valorização de aberturas de capítulos e parágrafos em diversos tipos de publicações, conferindo-lhes personalidade e impacto visual. Embora as capitulares contemporâneas não possuam os atributos artísticos das capitulares originais (medievais ou renascentistas), mesmo assim apresentam uma grande diversidade de usos, explorando não apenas o aspecto visual da letra em si, mas recursos como escala, contraste, texturas, tipografia e posição relativa ao texto, confirmando sua relevância no projeto gráfico contemporâneo. Este artigo analisa a ocorrência dessas letras em uma coleção de periódicos impressos reunida por alunos e professores da disciplina Projeto Visual III, do Curso de Design da Universidade Federal do Rio Grande do Sul, em Porto Alegre, Brasil. O desenvolvimento da pesquisa possibilitou a criação de categorias de organização das capitulares em relação ao texto que lhe segue, levando em conta diversos aspectos formais, o que permitiu o estabelecimento de uma taxonomia (classificação) das capitulares contemporâneas. Os resultados põem em evidência o caráter diverso das capitulares contemporâneas, não mais focado nas qualidades plásticas da letra em si, mas nas possibilidades de arranjo em relação ao texto, ao mesmo tempo em que preenchem uma lacuna na análise formal de um recurso gráfico/visual com grande potencial de uso.
\end{abstract}

drop caps, typography, graphic design, magazines
Drop caps are a widely used as graphics feature for enhancement of chapter and paragraph apertures in various publications, giving them personality and visual strength. Although the contemporary drop caps do not possess the artistic character of the medieval or Renaissance drop caps, they nevertheless present a great diversity, exploring more than the visual aspect of the letter itself but also features such as scale, contrast, textures, typography and position relative to the text, confirming its importance in the contemporary graphic design. This article analyzes the occurrence of drop caps in the collection of printed journals of the discipline Visual Design III, of Design Course of the Federal University of Rio Grande do Sul, in Porto Alegre, Brazil. For the purposes of the research, categories of drop caps organization were established in relation to the text that follows, allowing the establishment of a taxonomy for contemporary drop caps, highlighting their variations and possibilities of use. The article seeks to fill a gap in the analysis of a graphic/visual resource with great potential. 


\section{Introdução}

O uso de letras capitulares (ou apenas capitulares em português e espanhol; drop caps, em inglês; lettrine, em francês, capolettera, em italiano; Initialen ou Anfangbuchstabe, em alemão) é um dos recursos tipográficos mais antigos que se conhece e ainda em uso atualmente. Consiste em letras (ornamentadas ou não) de tamanho maior que o usado no texto que lhe segue, colocadas usualmente no início do primeiro parágrafo, e eventualmente nos demais, em livros e periódicos.

Etimologicamente, a palavra capitular provém do latim capita (nominativo e acusativo plural de caput-capitis), com o significado de cabeça, capítulo ou começo (MARcos, 2007). Assim, faz uma clara referência ao seu uso como elemento gráfico inicial de um capítulo ou parágrafo.

Sua origem está intimamente ligada ao uso das iniciais maiúsculas que passaram a diferenciar o início dos textos e a letra inicial de nomes próprios. Segundo Lupton e Miller (2011, p. 37) e Haley (2018), tanto os alfabetos gregos quanto os romanos originalmente utilizavam todas as letras com a mesma altura (minúsculas). A diferenciação entre maiúsculas e minúsculas (ou caixa-alta e caixa-baixa, no jargão editorial) passou a ser usual somente após o século viII, a partir das mudanças no sistema de escrita ocidental promovidas por Carlos Magno (742-814 d.C.). Segundo os autores, manuscritos carolíngios marcavam o início de uma frase com uma letra em tamanho maior, antecipando o uso contemporâneo de maiúsculas e minúsculas em um mesmo alfabeto, efetivamente consolidado na Europa a partir do século XVI. Um aspecto curioso desta origem está no fato de que Carlos Magno provavelmente era iletrado ou mesmo analfabeto (CARLOS MAGNO, 2018; MEGGS, 2000, p. 45); mesmo assim, incentivou o desenvolvimento da escrita por intermédio de um estudioso, Alcuino de York, que estabeleceu um padrão para a escrita com letras independentes umas das outras, conhecida como carolíngia minúscula, em substituição à letra cursiva usada até então. Esta característica disseminou-se pela Europa e foi favorável à invenção dos tipos móveis no século XV.

A diferenciação utilizando iniciais maiúsculas pode ser encontrada em manuscritos antigos, nos quais a primeira letra do parágrafo era desenhada em outra cor, geralmente o vermelho (minium e miniare, em latim, que significa zarcão ou vermelho, ou aplicar zarcão ou tinta vermelha), de modo a assinalar ao leitor o início de um parágrafo (Figura 1).

Esta estranha associação fica mais clara quando se verifica que nos manuscritos os detalhes tipográficos pequenos e delicados, como capitulares e versais, eram pintados com essa cor aplicada por artesãos chamados miniatores e cujo produto final era uma miniatura, ilustração de pequeno tamanho. 


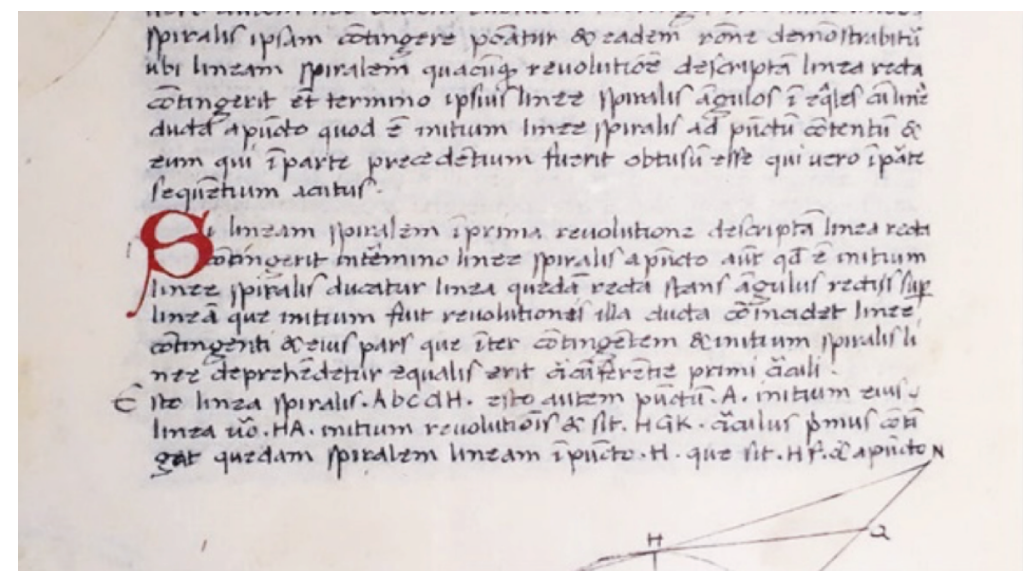

Figura 1 Detalhe do manuscrito Archimede (circa 1480), de Piero della Francesca (1416-1496), empregando iniciais de parágrafos maiúsculas em vermelho. Fonte: exposição "Piero della Francesca: la seduzione della prospettiva" - Museo Cívico Sansepolcro, Arezzo, Itália. Foto do autor, 2019.

Com o passar do tempo, as letras capitulares foram adquirindo importância, evoluindo para formas mais complexas, ampliando seu tamanho e acrescentando ornamentos figurativos ou abstratos, sempre guiados pelas mãos hábeis dos copistas (Figura 2) que criavam as capitulares adaptadas às características do texto ou da página, algumas vezes chegando ao exagero de ocupar toda a altura da página (Figura 3).

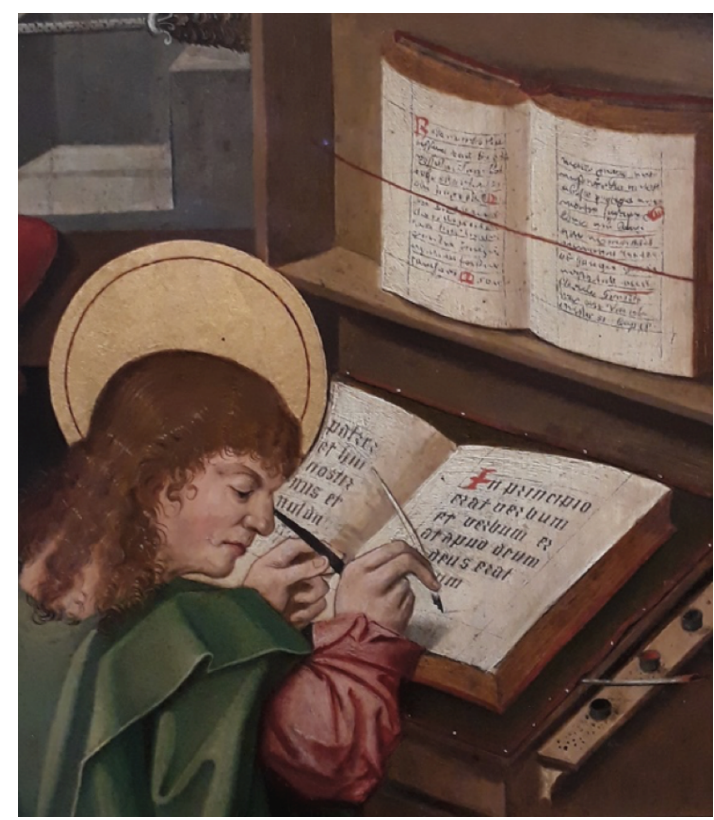

Figura 2 O Evangelista São Lucas (detalhe), 1478. Gabriel Mälesskircher (1430-1492). Fonte: Acervo do Museo ThyssenBornemisza, Madrid. Foto do autor, 2020. 


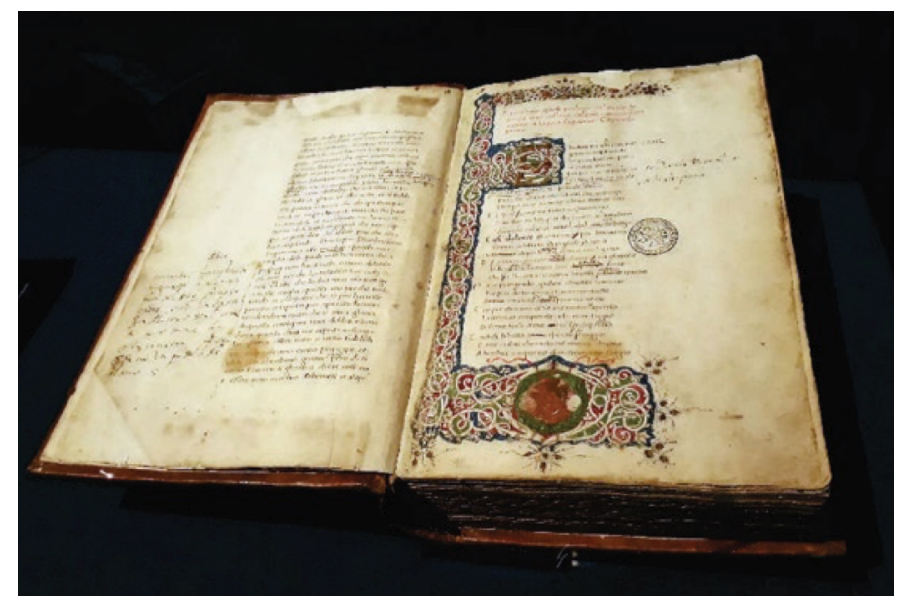

Figura 3 Página do manuscrito La vita e le gesta di Federico da Montefeltro duca d'Urbino (circa 1482-1488), de Giovanni Santi (1435? -1494). Fonte: coleção da Galleria Nazionale delle Marche, em exposição no Palazzo Ducale de Urbino, Itália. Foto do autor, 2019.

Para Marcos (2007), a utilização de letras capitulares teve seu apogeu na Idade Média, quando tinham não somente uma função ornamental - muitas vezes transformando este recurso gráfico em uma arte em si mesma -, mas uma vantagem prática e educativa: destacar o início de parágrafos ou de uma nova ideia no texto. Tendo em vista sua utilização em livros litúrgicos lidos em locais de pouca luz, por exemplo, uma inicial destacada torna um parágrafo facilmente encontrável (Figura 4).

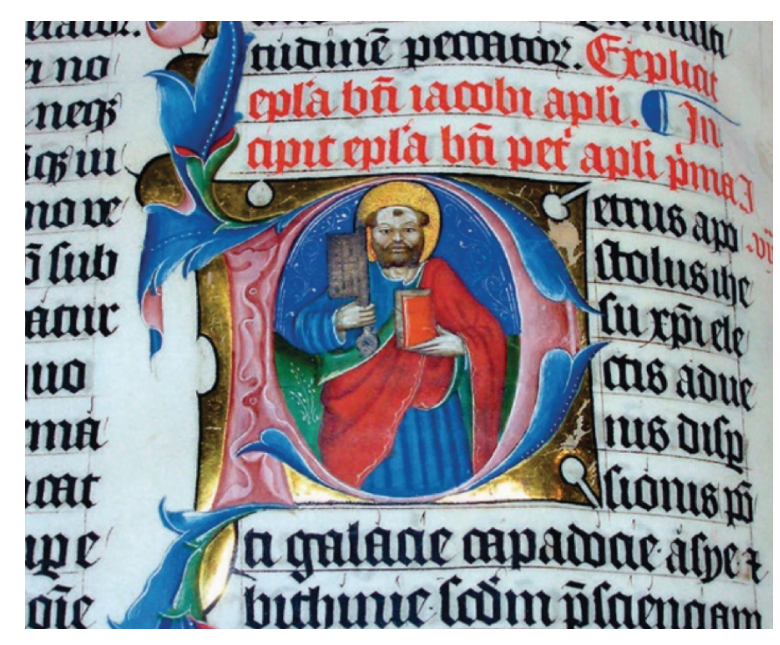

Figura 4 A inicial "P”, de Petrus. Detalhe da Bíblia da abadia de Malmesbury, Inglaterra, ilustrada por Gerard Brils, circa 1407. Fonte: <https://pt.wikipedia.org/wiki/ Iluminura $>$ Acesso em 06/04/2020. 
Pode-se afirmar que a consolidação da estrutura do texto como o conhecemos hoje foi possível após a invenção dos tipos móveis. Até então, não havia um livro igual a outro, pois todos eram edições únicas feitas à mão, conhecidas como códices (codex, em latim). Deste modo, a produção de livros era feita de acordo com as preferências individuais dos copistas. A invenção da prensa tipográfica com tipos móveis de Johannes Gutenberg (1400-1468), associada ao estabelecimento da escrita carolíngia como padrão europeu a partir no século XVI, contribuíram para dotar o texto de espaços entre palavras e de parágrafos para indicar uma mudança de ideia (LUPTON; MILLER, 2011, p. 38). Embora os incunábulos (livros editados entre 1455 e 1500) fossem impressos com tipos móveis, o espaço destinado às capitulares era deixado em branco, para posterior preenchimento à mão ou já utilizando tipos móveis especiais, em blocos individuais, entintados e impressos separadamente para cada cor (Figura 5).

Figura 5 Detalhe de Saltério em latim, impresso por Johan Fust e Peter Schoeffer, circa 1457. Capitular em azul e roxo, impressa separadamente do texto principal; maiúsculas do texto em vermelho. Fonte: Meggs, 2000, p. 67.

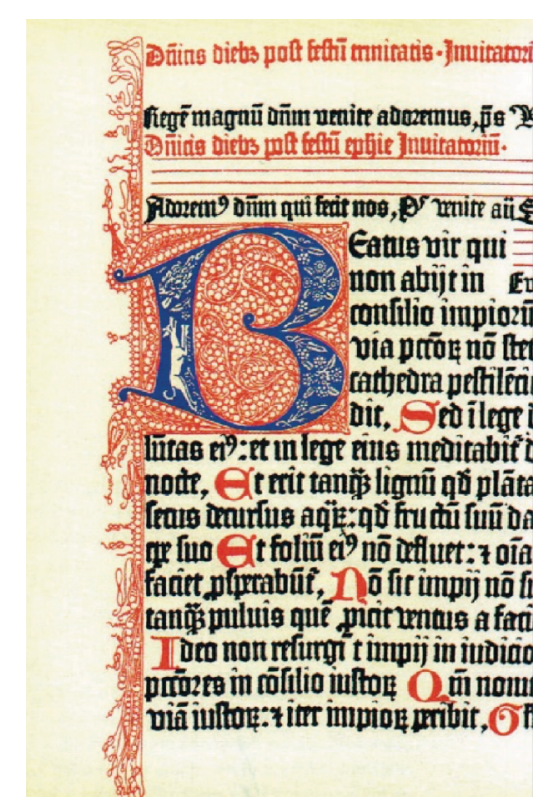

A legibilidade formal do texto moderno, associado à nova forma de ser impresso - necessitando a existência física de um tipo móvel para cada letra -, aparentemente teria levado as capitulares à perda de sua função de indicadoras do início das frases ou parágrafos, não sendo mais necessárias ou tendo reduzida sua importância no projeto gráfico (Figura 6), principalmente se comparada com exemplares anteriores, que utilizavam o ornamento como elemento gráfico importante (Figura 7 ).

Mesmo com toda esta variabilidade, o uso deste recurso gráfico manteve-se ao longo dos séculos, persistindo até nossos dias adaptado às características do projeto gráfico contemporâneo, o que coloca um importante problema de pesquisa: quais são as características das letras capitulares utilizadas em projetos editoriais contemporâneos? 


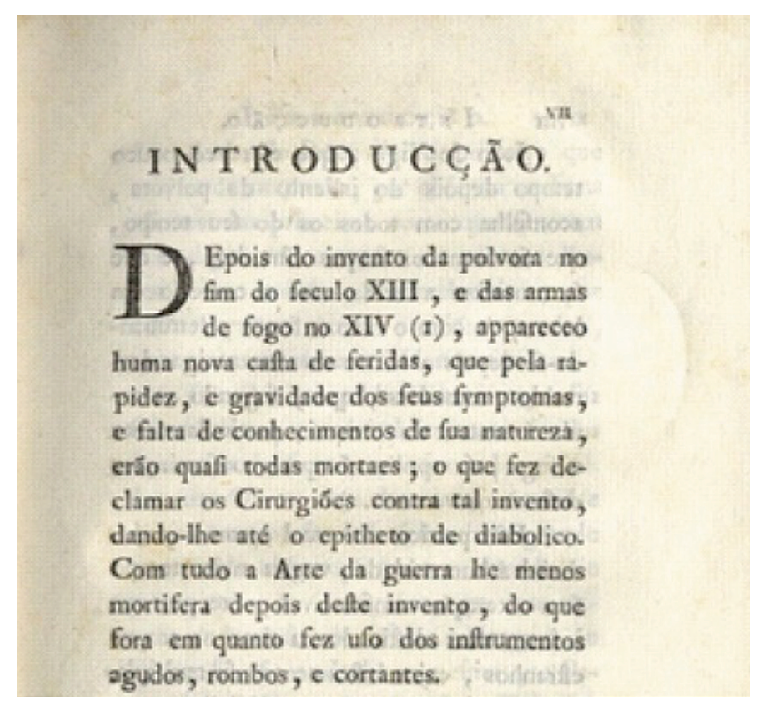

Figura 6 Capitular empregada no livro Dissertação sobre o methodo mais simples, e seguro de curar as feridas das armas de fogo..., de António de Almeida (1767-1839) Lisboa, Portugal, 1797. Fonte: Coleção de livros raros da Biblioteca Central da Universidade Federal do Rio Grande do Sul. Foto do autor, 2019.

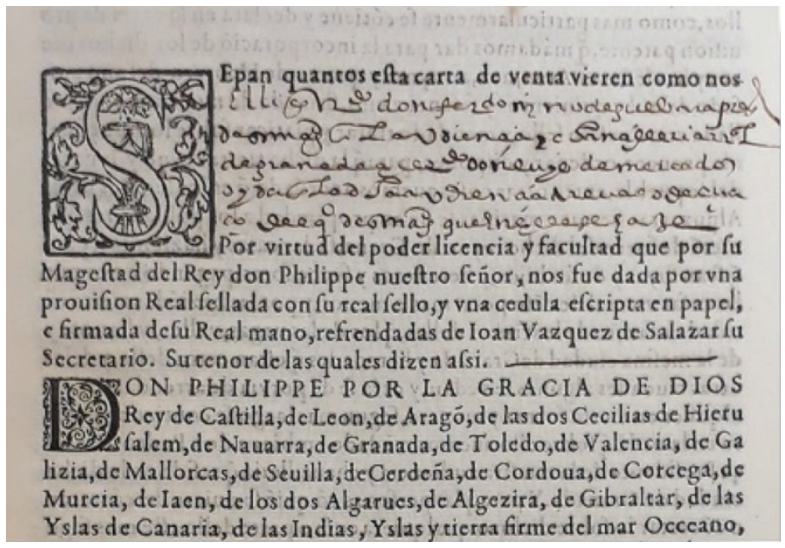

Figura 7 Capitulares do Documento de confiscación de los bienes de los moriscos rebelados, editado em Granada, Espanha, 1584. Fonte: Coleção da Fundación El legado andalusi, em exposição na mostra Los moriscos en el reino de Granada, no Cuarto Real de Santo Domingo, Granada, dezembro de 2019 a março de 2020. Foto do autor, 2020.

Deste modo, este artigo apresenta um levantamento sistematizado dos usos contemporâneos das capitulares, escolhendo como campo de investigação os periódicos impressos, onde elas são utilizadas de forma recorrente, propondo uma classificação taxonômica. Originária do grego, da junção do verbo tassein ( $\tau \alpha \sigma \sigma \varepsilon \tilde{\imath} v$ ) classificar e nomos ( vó $\mu$ oৎ) que significa lei ou ciência, a taxonomia é usualmente associada à classificação de seres vivos, mas pode ser entendida como um sistema abrangente de classificação ou categorização geral, aplicável à outras ciências e campos de estudo, buscando sempre maior objetividade. Aplicada ao design gráfico, a taxonomia das letras capitulares contemporâneas permite uma melhor compreensão e entendimento dos usos em projetos gráficos, e oferece a pesquisadores e designers um amplo panorama nacional e internacional deste recurso que atravessa os séculos, adaptando-se constantemente.

\section{Metodologia}

Para conhecer as peculiaridades das letras capitulares contemporâneas e as características das soluções adotadas no contexto atual, foi realizada uma pesquisa na coleção de periódicos da disciplina Projeto Visual III, oferecida no curso de Design Visual da Universidade Federal do Rio Grande do Sul, em Porto Alegre, Brasil. Esta coleção foi reunida 
por critérios de conveniência e disponibilidade, com exemplares impressos comercializados e gratuitos, de origem brasileira e estrangeira, recolhidos por professores e alunos da disciplina desde 2010, e se constitui em importante fonte de consulta para os exercícios editoriais propostos semestralmente.

Os exemplares compreendem periódicos de natureza diversa (revistas de bordo, de entretenimento, de notícias, científicas, culturais etc.), além de jornais diários. A diversidade de títulos e a origem geográfica das publicações oferecem um amplo panorama internacional de periódicos contemporâneos, e contribuem para a formação do repertório gráfico dos alunos da disciplina. A realização da pesquisa focada na categoria periódicos mostrou-se uma ótima alternativa, uma vez que essas publicações apresentam grande diversidade de capitulares em um mesmo exemplar, sobretudo quando comparadas com a categoria livros, na qual as capitulares não costumam ser tão diversas, quase sempre limitadas a um único padrão que se repete ao longo da obra.

Todos os exemplares da coleção (cerca de 500) foram analisados por meio de uma Análise Temática (souzA, 2019), onde as diversas reportagens de cada periódico foram observadas e categorizadas. Nesse tipo de procedimento os documentos que são objeto da análise são agrupados em categorias dependendo da sua similaridade, e cada uma dessas categorias é chamada de "tema”. A análise temática pode ser realizada tanto em temas predefinidos ou em temas que surgem ao longo do processo, sendo este o caso do presente estudo. É importante salientar que, em muitos casos, um mesmo periódico apresentava reportagens com e sem capitulares.

A metodologia da Análise Temática possui cinco etapas: a familiarização com os dados, a geração de códigos iniciais, a busca pelos temas, a revisão dos temas, a definição e nomeação dos temas e a redação do relatório. A familiarização com os dados diz respeito ao contato prévio com os dados a serem analisados, no presente estudo esta familiarização aconteceu ao longo da coleta de dados ocorrida entre os anos de 2010 a 2020 dentro da disciplina de Projeto Visual III.

A etapa de geração dos códigos iniciais diz respeito a uma criação de agrupamentos ou "temas" prévios, que serão posteriormente refinados. No presente estudo esses códigos iniciais também aconteceram ao longo do processo de coleta, onde os pesquisadores começaram a perceber as peculiaridades das capitulares utilizadas em periódicos da coleção.

Já a criação dos temas tem como objetivo criar de fato categorias e subcategorias até que não existam exemplares não classificados ou que estes sejam pouco significativos dentro da coleção. Essa etapa é seguida da etapa de revisão dos temas, onde os temas e a coleção são refinados uma vez mais. Essas etapas ocorreram no início de 2020, quando os pesquisadores decidiram consolidar a presente proposta de classificação. Nessa etapa as categorias (ou temas) prévios foram revisados e tentou-se inserir as diferentes apresentações das capitulares dentro das categorias visuais criadas até que se tivesse um universo de alguns poucos casos especiais. 
A definição e nomeação dos temas diz respeito à definição final dos temas, incluindo as subcategorias (se for o caso) bem como a criação da identificação dos temas, ou seja, a criação dos nomes de cada categoria. Essa definição e nomeação é o resultado do presente estudo, que também pode ser inserido na etapa de "redação do relatório".

Tendo em vista que o termo "tema" utilizado na teoria da Análise Temática (souzA, 2019) pode criar confusão em relação a outros significados da palavra, será utilizado neste estudo o termo "categorias", que é mais comumente utilizado para descrever agrupamentos de informação.

Assim, ao longo do processo de investigação foram definidas categorias que procuram contemplar o maior número de casos possível, como será demonstrado a seguir. Essas categorias, porém, não são estanques ou definitivas, pois uma mesma capitular pode se enquadrar em mais de uma delas. Por exemplo, a capitular mostrada na Figura 8 pode ser classificada como média (altura de 5 linhas), empregando fonte distinta do texto, limitada à mancha gráfica, com forte contraste.

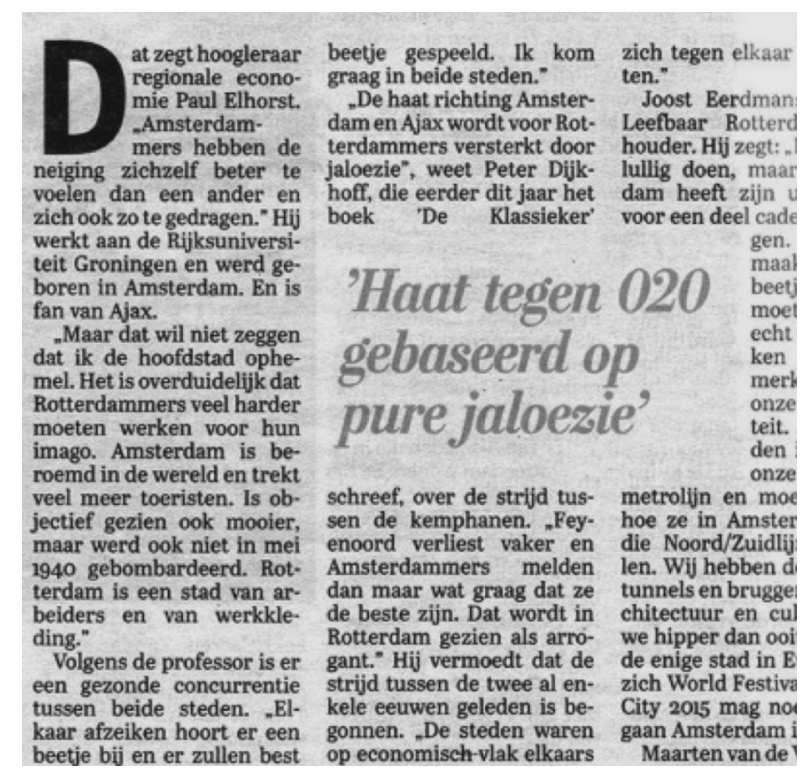

Figura 8 Capitular média, com fonte distinta da fonte do texto, limitada à mancha gráfica e com forte contraste. Fonte: Jornal De Telegraaf, Holanda, 27 de outubro de 2015, p. 10.

\section{Categorias de letras capitulares}

A primeira providência ao iniciar a pesquisa foi registrar o uso ou não de letras capitulares em reportagens que compõem os periódicos disponíveis, o que sensibilizou os pesquisadores para a importância das capitulares e seu uso como recurso expressivo na diagramação das matérias jornalísticas. Para Bringhurst (2011, p. 73), sempre que 
uma página apresentar muitos elementos gráficos (título, epígrafe, notas, chamadas, imagens, legendas etc., como costuma ser o caso dos periódicos), a abertura do texto deve ser destacada, sendo a letra capitular uma boa alternativa. Ao se comparar uma reportagem que inicia sem este recurso com outra que o utiliza (Figura 9), percebe-se nesta última a criação de um ponto de atração visual que marca o início do texto e convida à leitura, demonstrando a força gráfica das capitulares.
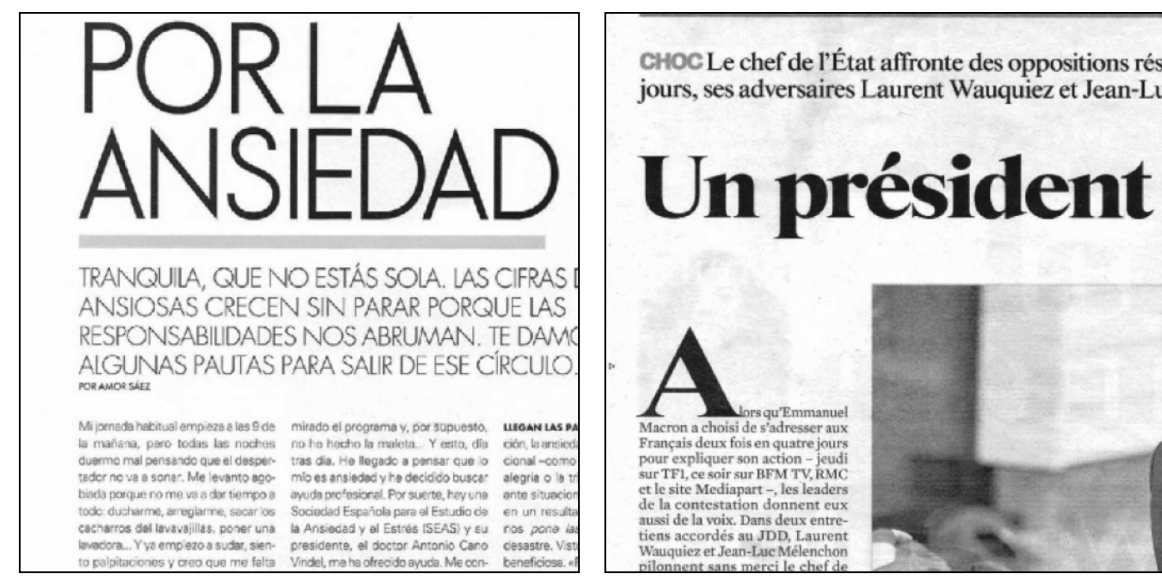

Figura 9 Esquerda: texto que não emprega capitulares para o início do parágrafo. Fonte: Revista Elle, Espanha, fevereiro de 2006, p. 144. Direita: texto que emprega capitular para o início do parágrafo. Fonte: Jornal Le Journal du Dimanche, França, no 3718, 15 de abril de 2018, p. 2.

Foi possível observar a simplificação das capitulares contemporâneas em relação às capitulares históricas. Caracterizadas por serem quase obras gráficas em si, as capitulares históricas eram elementos destacados, explorando linhas, formas, texturas e eventualmente cores com requinte e virtuosidade, constituindo-se em forte elemento gráfico. As capitulares contemporâneas, via de regra limitam-se a empregar as fontes tipográficas existentes, adotando variações no tamanho, disposição e contraste, aspectos que não eram explorados nas capitulares históricas (Figura 10), como será apresentado mais adiante.

Uma vez selecionados os exemplares que atendiam os requisitos da pesquisa, foram estabelecidas as categorias de análise, buscando contemplar as principais diferenças existentes entre os exemplos. Desta forma, foram definidas as seguintes categorias:

1. Tamanho

2. Posição em relação à mancha gráfica

3. Diferenciação tipográfica

4. Contraste

5. Aspectos tipográficos complementares

6. Acentuação e sinais gráficos

7. Casos especiais 

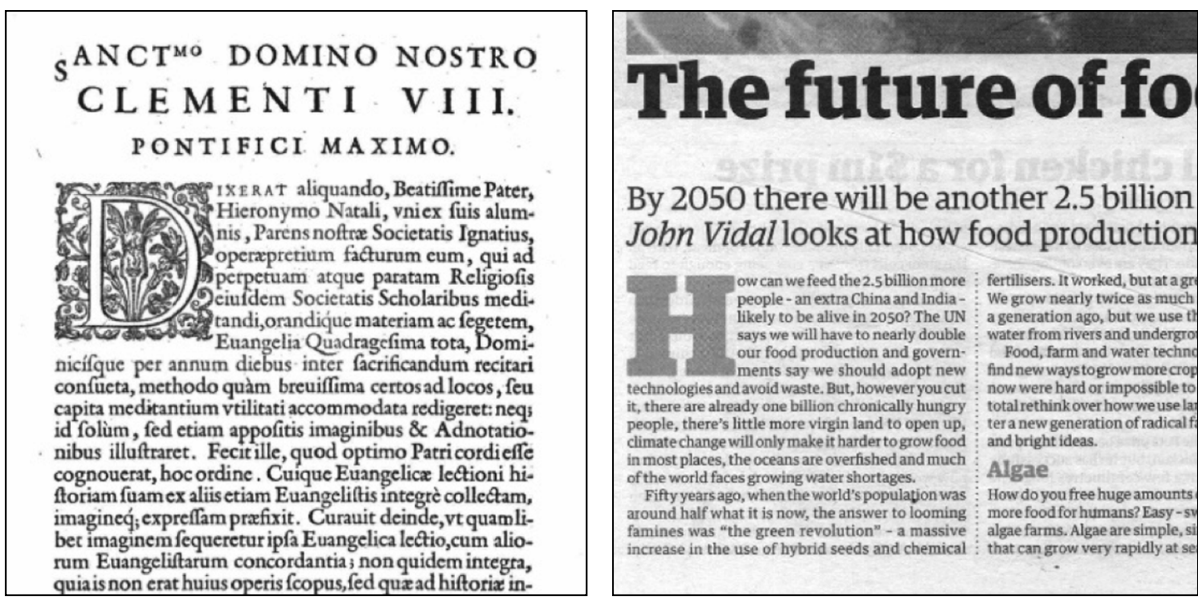

By 2050 there will be another 2.5 billion John Vidal looks at how food production

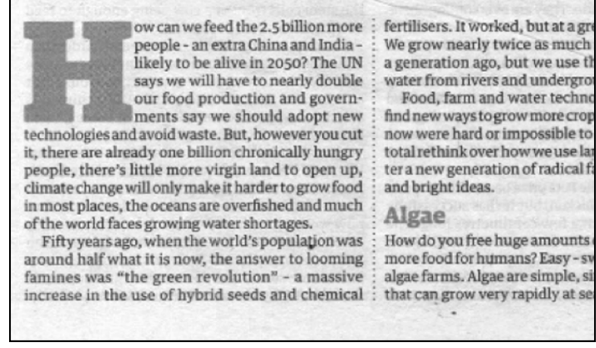

Figura 10 Esquerda: capitular histórica caracterizada pelo aspecto decorativo. Fonte: Annotationes et meditationes in Evangelia..., de R. P. Hieronymi Natalis (1507-1580), Antuérpia, Bélgica, 1707. Coleção de livros raros da Biblioteca Central da Universidade Federal do Rio Grande do Sul. Direita: capitular contemporânea, caracterizada pela simplicidade. Fonte: Jornal The Guardian Weekly, Inglaterra, 10 de fevereiro de 2012, p. 25.

É importante salientar que a classificação procura ser o mais abrangente possível, mas isso não impede que novas categorias sejam incluídas uma vez detectadas novas formas de capitulares em publicações que não fazem parte da coleção analisada. A seguir, são apresentados exemplos que ilustram as diversas categorias.

\subsection{Tamanho}

O tamanho diz respeito às dimensões relativas da letra capitular em relação à coluna ou à página. Esta categoria está dividida em cinco subcategorias: muito pequenas, pequenas, médias, grandes e gigantes (Figura 11), que contemplam o tamanho relativo das capitulares em relação à coluna. Nos periódicos analisados, a categoria média (com altura entre 5 e 10 linhas) foi a que apresentou o maior número de ocorrências. Enquanto as capitulares muito pequenas ocupam uma ou duas linhas do texto, com baixo impacto gráfico, as capitulares gigantes ocupam várias linhas, muitas vezes expandindo-se para fora da mancha gráfica, criando um efeito gráfico expressivo e adquirindo grande protagonismo na composição, algumas vezes constituindo-se em elementos gráficos independentes. Entre esses dois extremos, as capitulares pequenas, médias ou grandes conseguem proporcionar um bom destaque ao início de um parágrafo. 
Muito pequenas

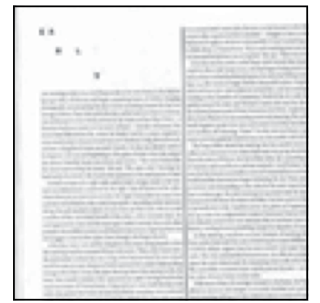

Pequenas

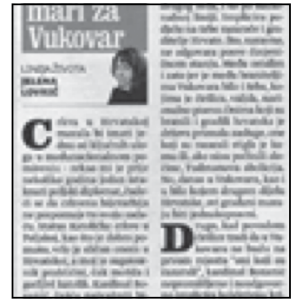

Médias

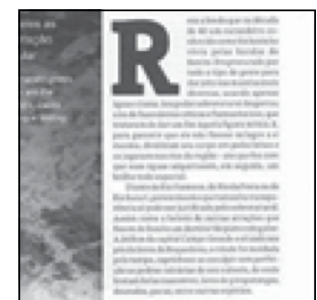

Grandes

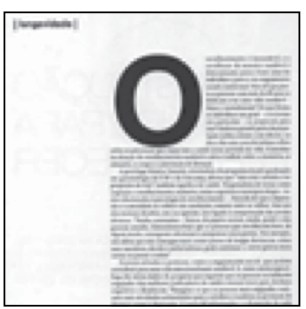

Gigantes

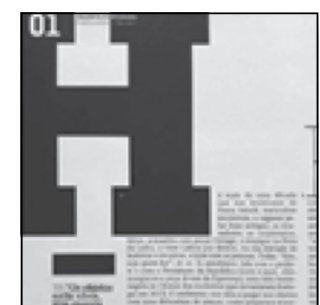

Figura 11 Classificação das capitulares quanto ao seu tamanho. Fonte: Jornal The New York Times Magazine, EUA, 22 de julho de 2018, p. 34; Jornal Jutarnji, Croácia, 2 de maio de 2013, p. 18; Revista de bordo Azul Magazine, Brasil, agosto de 2015 p. 87; Revista da Cultura, Brasil, dezembro de 2017, p. 28; Revista de bordo UP TAP, Air Portugal, Portugal fevereiro de 2018, p. 34.

\subsection{Posição em relação à mancha gráfica}

Esta categoria contempla a posição da capitular em relação à coluna (ou mancha do texto). Embora predominem as capitulares na posição interna, contidas nos limites da coluna/mancha gráfica, pois este é o padrão de programas de editoração, outras posições são encontradas: externa, superior, próxima e afastada. É possível proporcionar mais destaque às capitulares colocando-as em posições não usuais, embora correndo o risco de desvincularem-se do texto, como no caso da posição afastada, quanto a letra pode assumir um caráter de elemento gráfico independente, sem relação com o texto (Figura 12).
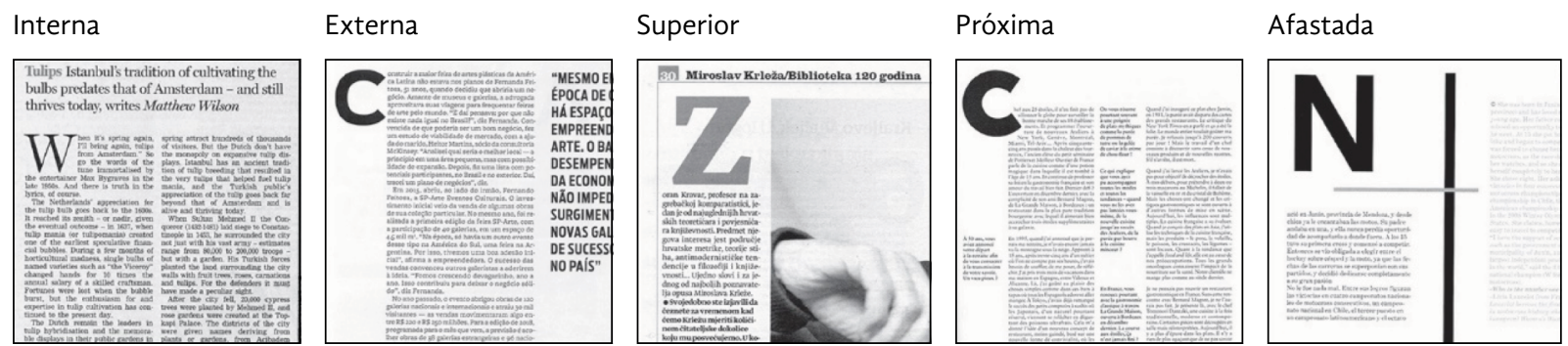

Figura 12 Classificação das capitulares em relação à mancha gráfica. Fonte: Jornal Financial Times, suplemento House \& Home, EUA, 4 de maio de 2013, p. 12.; Revista Pequenas Empresas Grandes Negócios, Brasil, março de 2018, p. 46.; Jornal Jutarnji, Croácia, 2 de maio de 2013, p. 30.; Revista de bordo Magazine, Air France, França, junho de 2015, p. 64.; Revista de bordo Alta, Aerolineas Argentinas, Argentina, agosto de 2017, p. 140.

\subsection{Diferenciação tipográfica}

Basicamente existem duas subcategorias para esta classificação: capitulares que utilizam a mesma fonte ou família tipográfica do corpo de texto principal e as capitulares que utilizam fontes diferentes daquelas aplicadas no corpo de texto. Na Figura 13, por 
exemplo, no primeiro caso a capitular se apresenta com a mesma fonte do texto principal, um tipo com serifa. Já no segundo caso, a fonte utilizada na capitular é uma fonte sem serifa, enquanto que no corpo de texto principal a fonte é serifada.
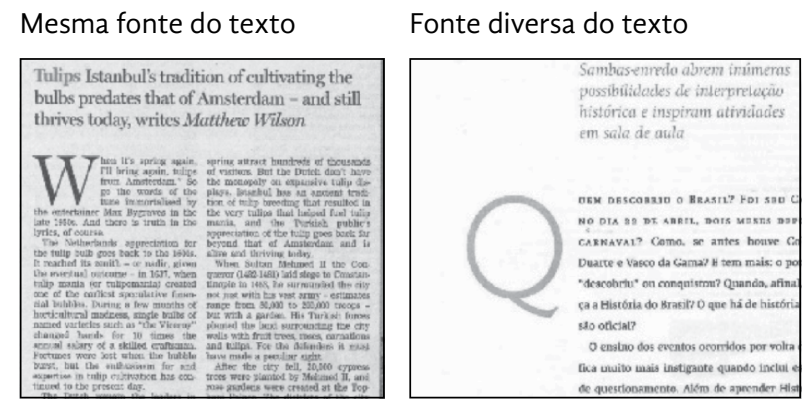

Figura 13 Classificação das capitulares em relação à tipografia. Fonte: Fonte: Jornal Financial Times, suplemento House \& Home, EuA, 4 de maio de 2013, p. 12.; Revista de História da Biblioteca Nacional, Brasil, fevereiro de 2010, p. 80.

\subsection{Contraste figura-fundo}

O contraste diz respeito à facilidade com que se percebe a letra em relação ao fundo onde está colocada, o que contribui para uma boa visualização das capitulares, podendo ocorrer por cor ou escala (tamanho). Algumas vezes, a redução do contraste ocorre como opção compositiva para não destacar demasiadamente a capitular (Figura 14). No presente estudo as capitulares foram classificadas em duas categorias: contraste por cor, onde existe uma diferenciação marcante e explícita entre a capitular e o fundo onde o texto está escrito; contraste por tamanho, onde a capitular se apresenta com um tamanho significativamente maior que o corpo de texto, e que
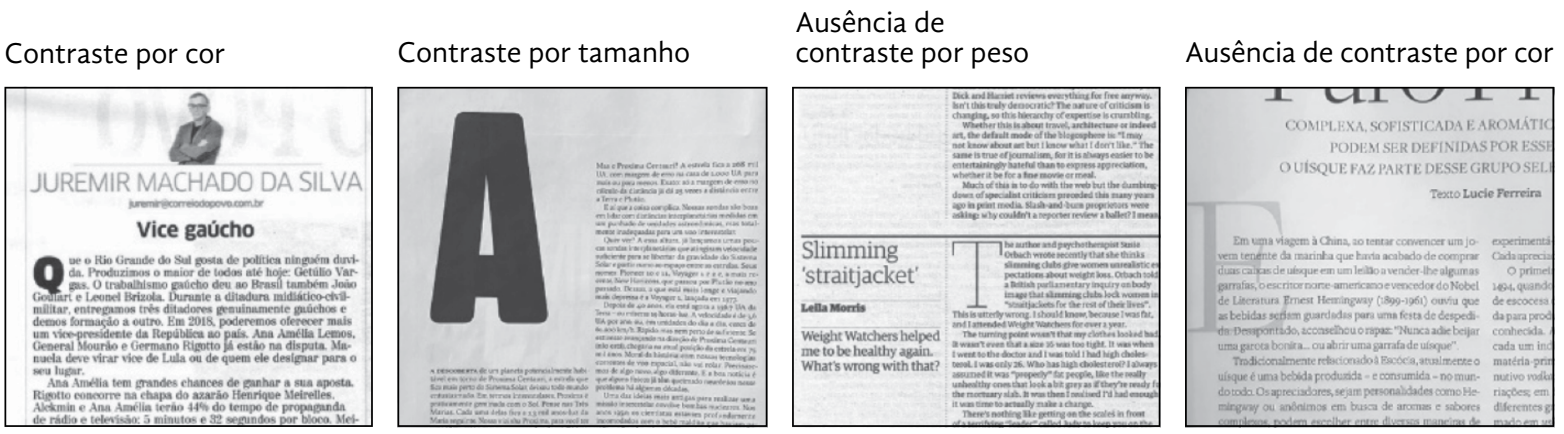

Figura 14 Classificação das capitulares em relação ao contraste. Fonte: Jornal Correio do Povo, Brasil, 9 de agosto de 2018, p. 2.; Revista Superinteressante, Brasil, novembro de 2016, p. 36.; Jornal The Guardian Weekly, Reino Unido, 10 de fevereiro de 2012, p. 24.; Revista Day by Day, Brasil, ano 8, n. 8, 2016. 
também pode ser considerado um caso específico da categoria Tamanho (item 3.1). Para ressaltar a relevância desta categoria, são apresentados dois exemplos onde este contraste não ocorre.

\subsection{Aspectos tipográficos complementares}

Esta categoria trata dos aspectos gráficos complementares ou acessórios que podem ser associados às letras, de modo a conferir-lhes personalidade, mas que não dizem respeito à tipografia propriamente dita. Uma cor de fundo, por exemplo, pode ser utilizada para contribuir para a sua diferenciação em relação ao texto principal, porém esta não é totalmente tipográfica, mas sim uma interferência visual criada pelo designer ou diagramador. Grafismos aplicados à letra, de modo a diferenciá-la da fonte original, também foram encontrados na coleção de periódicos. Outro recurso gráfico acessório são as deformações da tipografia original, em que a capitular é esticada ou torcida, alterando a fonte de modo a criar uma diferenciação visual (Figura 15). Este último recurso é relativamente comum, pois faz com que a capitular não ocupe muito espaço na coluna, sobretudo letras de maior largura.
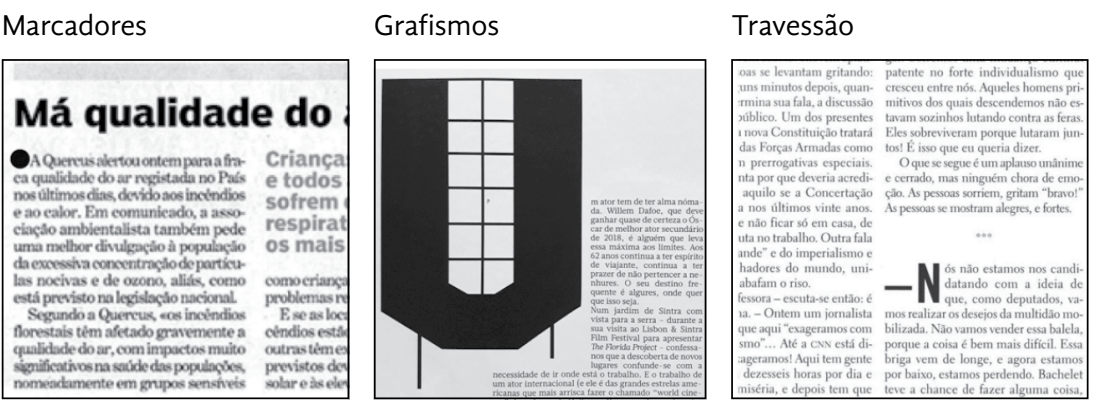

Figura 15 Classificação das capitulares quanto a aspectos tipográficos complementares. Fonte: Suplemento do jornal dna, Índia, 11 de abril de 2013, p. 4.; Revista de bordo UP TAP Air Portugal, Portugal, fevereiro de 2018, p. 102.; Revista L'Obs, França, n. 28350, 7 de março de 2019, p. 74 .

\subsection{Acentuação e sinais gráficos}

1 Diz-se de ou sinal gráfico que serve para diferenciar letras ou palavras (ex.: sinal diacrítico; os acentos, o til e a cedilha são diacríticos). Disponível em: <https:// dicionario.priberam.org/ diacr\%C3\%ADtico> Acessado em: 20 set. 2020.
Essa categoria contempla as capitulares que apresentam sinais gráficos, como aspas, e/ou diacríticos ${ }^{1}$ (acentos, cedilhas, entre outros) em sua composição. Foram encontrados poucos casos de capitulares acentuadas, certamente pela menor ocorrência deste sinal diacrítico na primeira letra das palavras (ao menos em português). Sinais gráficos como apóstrofos utilizados junto às capitulares também foram encontrados no acervo pesquisado, mas em revistas cujo idioma contempla este sinal com maior intensidade que o português. 
O uso de aspas ocorre de duas maneiras: apresentadas sozinhas ou acompanhadas de uma letra ou palavra, que nesse estudo são descritas como aspas acompanhadas podendo ser aspas elevadas (" ”) ou francesas («»), estas últimas também conhecidas como aspas em linha (Figura 16).

Acentuadas

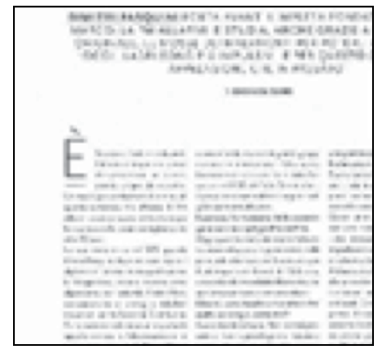

Apóstrofos

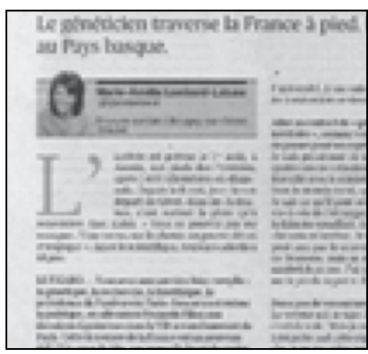

Aspas

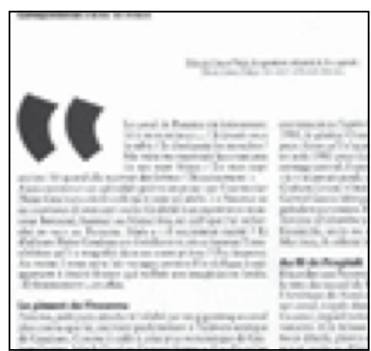

Aspas acompanhadas

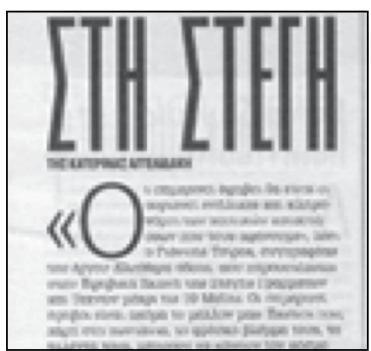

Figura 16 Classificação das capitulares quanto à acentuação e sinais gráficos - I. Fonte: Revista UP Magazine Arezzo, Itália, n. 7, inverno de 2019, p. 30.; Jornal Le Figaro, França, 19 de maio de 2013, p. 20.; Revista de bordo Magazine, Air France, França, junho de 2015, p. 130.; Revista $T a \lambda \kappa$, Grécia, 15 de maio de 2013, p. 42.

2 São sinais tipográficos utilizados para marcar posições em uma página, geralmente utilizados em listas como por exemplo o sinal

3 São sinais tipográficos diversos que acompanham uma fonte tipográfica, como o símbolo de coração

Embora seja um recurso gráfico relativamente modesto e de baixo impacto, marcadores tipográficos, ${ }^{2}$ símbolos ou caracteres especiais ${ }^{3}$ também foram encontrados, substituindo capitulares tipográficas. O travessão indicando início de fala ou diálogo foi encontrado poucas vezes. Esta situação acrescenta um elemento gráfico na capitular, criando uma espécie de "ruído" gráfico (Figura 17).

Marcadores

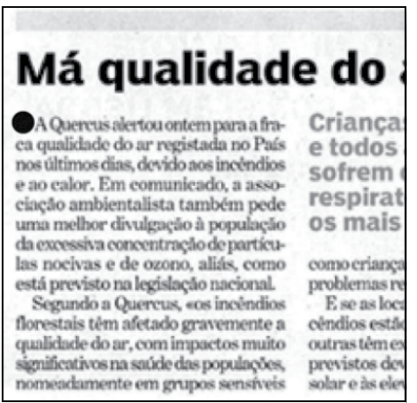

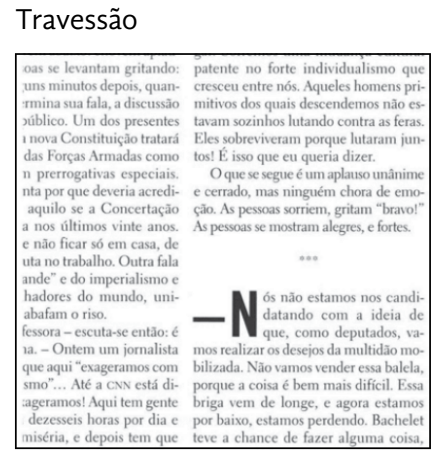

Figura 17 Classificação das capitulares quanto à acentuação e sinais gráficos - II. Fonte: Jornal Destak, Portugal, 6 de setembro de 2013, p. 6. Revista Piauí, Brasil, setembro de 2013, p. 37. 
Letra "I"

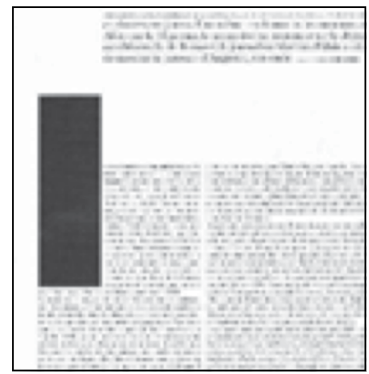

Palavras como capitular

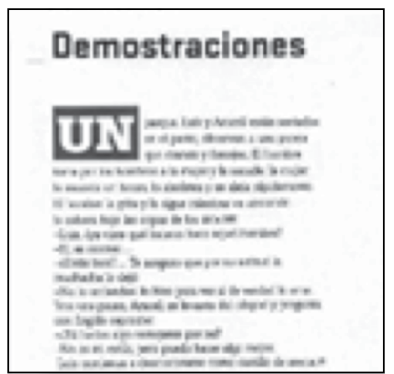

Falsas capitulares

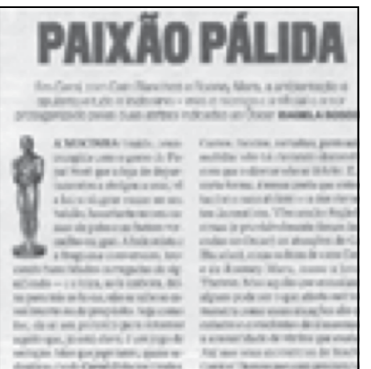

QR-code

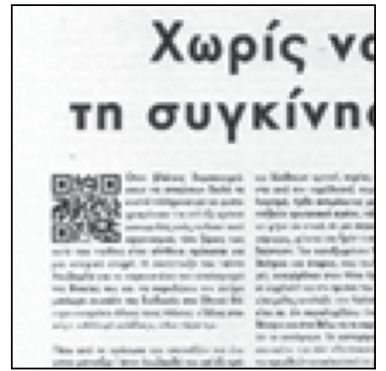

Figura 18 Classificação das capitulares; categorias especiais. Fonte: Revista Le Magazine du monde, França, 5 de janeiro de 2019, p. 27.; Revista de Bordo Escala, Aeroméxico, México, março de 2008, p. 164.; Revista de bordo Alta, Aerolineas Argentinas, Argentina, agosto de 2017, p. 148.; Revista Veja, Brasil, 20 de janeiro de 2016, p. 93.; Jornal Metropolis, Grécia, 17 a 23 de maio de 2013 , p. 31.

\subsection{Casos especiais}

$\mathrm{Na}$ categoria de casos especiais encontram-se situações particulares (Figura 18) que não foram identificadas em outros casos, ou seja, são casos muito singulares e por isso de difícil classificação em outras categorias. Esse tipo de situação é previsto dentro da Análise Temática (sOUZA, 2019)

A letra "I" é um desses casos, pois quando a capitular utiliza fonte sem serifa, seu aspecto tende a ser confundido com um simples retângulo. Outro caso especial é o uso de palavras como capitulares. Relativamente raro, mesmo assim foram localizados alguns casos, mas usando palavras pequenas (preposições, artigos, pronomes). Foram identificas falsas capitulares, elementos gráficos ou imagens utilizadas como se fossem capitulares. O uso de QR code como capitular é um caso especial interessante, pois acrescenta um outro caráter utilitário às marcações de início de parágrafo, podendo conectar o leitor ao site da revista ou dando acesso a dados complementares da reportagem.

\section{Discussão dos resultados}

O objetivo do presente estudo foi analisar a ocorrência de letras capitulares em uma coleção acadêmica de periódicos com cerca de 500 exemplares das mais variadas linhas editoriais. Para tanto foi utilizada a metodologia da Análise Temática (souzA, 2019) onde as diversas reportagens de cada periódico foram observadas e categorizadas ao longo do processo de análise. É importante salientar que, em muitos casos, um mesmo periódico apresentava reportagens com e sem capitulares, e que o número total de casos supera o número de exemplares, pois várias reportagens costumam compor um periódico. Deste modo, os autores optaram por uma abordagem não quantitativa 
de exemplares, tendo em vista que os periódicos analisados são um recorte ínfimo da produção editorial contemporânea, reunidos por critérios de conveniência; embora possam representar diversos aspectos do panorama editorial mundial, referem-se ao contexto que foi objeto de análise, sendo suas conclusões relativas a esta realidade específica, não podendo ser generalizados. As categorias propostas não têm a pretensão de ser dogmáticas, pois correspondem a um ponto de vista dos autores e foram estabelecidas levando em conta os critérios mais proeminentes de cada caso, procurando contemplar diversos aspectos gráficos das capitulares e estando abertas para novas inclusões e modificações.

Como principal conclusão, é possível afirmar que, com o advento da diagramação digital no final do século $\mathrm{xx}$, as capitulares deixaram de ser condicionadas à existência de uma matriz física para cada letra, sendo usadas com uma maior liberdade. No design gráfico contemporâneo é possível encontrar capitulares com os mais diversos aspectos e arranjos, embora raramente com o tratamento gráfico requintado e artesanal que lhe era concedido nos períodos medieval e renascentista. Não é mais explorado o aspecto visual das letras em si, mas seu uso enquanto parte da composição gráfica da página foi ampliado com grandes variações tipográficas. Assim como outros recursos encontrados em textos impressos históricos ainda são empregados no projeto gráfico contemporâneo (mancha gráfica, recuos, parágrafos, margens etc.), as capitulares também seguem em uso, mas adotando uma linguagem e diagramação adequadas aos novos tempos. Despojadas do aspecto decorativo e ornamental das capitulares antigas ou históricas, as capitulares contemporâneas podem ser caracterizadas como letras em dimensões maiores do que o texto que lhe segue, apresentando um posicionamento variável e não mais restrito aos limites da mancha gráfica. Se por um lado parece ter havido um empobrecimento do aspecto gráfico das letras, por outro lado passaram a desfrutar de uma liberdade compositiva muito maior, deixando de ser contidas pela mancha gráfica ou pelas matrizes físicas, explorando novas possibilidades na composição da página.

\section{Considerações finais}

Ao longo da história, as capitulares sempre foram objeto de atenção dos trabalhadores e artistas dedicados à diagramação de textos escritos, como os monges copistas, por exemplo. Com o passar do tempo, diagramadores e designers passaram a se ocupar delas, quando é possível perceber uma mudança de enfoque: da exploração das qualidades plástico/formais da letra em si para a exploração de suas possibilidades enquanto elemento de composição da página impressa. Nessa mudança, a perda das qualidades artísticas virtuosas da letra foi compensada pelas novas possibilidades de arranjo em relação ao texto. 
A realização desta pesquisa permitiu identificar a expressiva presença de letras capitulares em publicações periódicas no panorama editorial mundial contemporâneo, atestando sua permanência enquanto elemento gráfico/visual, além de revelar uma grande diversidade compositiva. Cumprindo a mesma função de suas antecessoras históricas - destacar o início de um texto -, as capitulares contemporâneas se diferenciam por uma maior liberdade em termos de posicionamento, dimensões, famílias tipográficas e outros detalhes. Por outro lado, deixam de explorar detalhes ornamentais da letra em si, geralmente empregando fontes já existentes em escala diferente do texto que lhe segue.

Finalmente, a classificação das capitulares em categorias taxonômicas permite ter uma compreensão mais ampla deste recurso gráfico, uma vez que apresenta uma espécie de quadro geral de modos de utilização. Longe de esgotar as possibilidades gráficas das capitulares, a classificação é um processo em andamento e sua divulgação procura justamente ampliar a percepção sobre as possibilidades expressivas deste recurso tipográfico, aberto para eventuais novas categorias.

\section{Referências}

Bringhurst, R. Elementos do estilo tipográfico. São Paulo: Cosac Naify, 2011. CARLos Magno. In: Wikipedia: a enciclopédia livre. Wikimedia, 2018. Disponível em: https://pt.wikipedia.org/wiki/Carlos_Magno. Acesso em: 18 mar. 2020.

HALEY, A. Lowercase letters. Fontology. 2018. Disponível em: https://www.fonts. com/content/learning/fontology/level-1/type-anatomy/lowercase-letters. Acesso em: 21 mar. 2020.

HALEY, A. Raised and dropped initials. Fontology. 2018. Disponível em: https:// www.fonts.com/content/learning/fontology/level-4/fine-typography/ raised-and-dropped-initials. Acesso em: 6 abr. 2020.

Lupton, E.; Miller, A. Design, Escrita, Pesquisa: a escrita no design gráfico. Porto Alegre: Bookman, 2011.

MARCOS, J. J. Letras capitulares: concepto, história, evolucion y uso tipográfico. Plasencia: [s.n.], 2007. Disponível em: http://guindo.pntic.mec.es/jmagoo42/ CAPITULARES.pdf. Acesso em: 6 maio 2020.

MEGGS, P. в. História del diseño gráfico. México D.F.: McGraw-Hill, 2000.

souzA, L. K. Pesquisa com análise qualitativa de dados: conhecendo a Análise Temática. Arquivos Brasileiros de Psicologia, Rio de Janeiro, v. 71, n. 2, p. 5167, 2019. Disponível em: http://pepsic.bvsalud.org/scielo.php?script=sci arttext\&pid=S1809-52672019000200005\&lng=pt\&nrm=iso\&tlng=pt. Acesso em: 6 set. 2020 . 


\title{
Sobre os autores
}

\author{
Airton Cattani \\ <aacc@ufrgs.br> \\ Doutor, Professor do Curso de Design da UfRGS, \\ Porto Alegre, Rs, Brasil. \\ Davi Frederico do Amaral Denardi \\ <denardi.davi@gmail.com> \\ Mestre, professor do curso de Cinema e Animação, UFPel. \\ Pelotas, Rs, Brasil
}

Artigo recebido em/Submission date: 18/5/2020

Artigo aprovado em/Approvement date: 12/12/2020 